\title{
VIDEO-ASSISTED OBSERVATION IN MITRAL VALVE SURGERY
}

Yukihiro Kaneko, MD, ${ }^{a}$ Tadasu Kohno, MD, ${ }^{a}$ Toshiya Ohtsuka, MD, ${ }^{a}$ Toshiro Ohbuchi, MD, ${ }^{a}$ Akira Furuse, MD, ${ }^{a}$ and Toshio Konishi, MD, ${ }^{b}$ Tokyo and Yokohama, Japan

Exposure of the tissue to be operated on is of central importance to the success of surgery. Operation on the mitral valve may be difficult when exposure is not satisfactory, as is the case when the left atrium is not enlarged or the atrioventricular ring is adhering to the pericardium because of a previous operation. By using video-assisted visualization in combination with direct observation, we were able to achieve a highly satisfactory view of the mitral valve in all such cases. We describe a method of

From the Department of Cardiothoracic Surgery, Faculty of Medicine, University of Tokyo, ${ }^{\mathrm{a}}$ Tokyo, Japan, and the Department of Cardiovascular Surgery, Yokohama Rosai Hospital, ${ }^{\text {b }}$ Yokohama, Japan.

Accepted for publication May 18, 1995.

J ThoraC CARdiovasC SuRG 1996;111:279-80

Copyright $(\mathbb{C} 1996$ by Mosby-Year Book, Inc.

$0022-5223 / 96 \$ 5.00+0 \quad \mathbf{1 2 / 5 4 / 6 6 3 3 2}$ video-assisted visualization used for mitral valve observation and detail its benefits.

Application of videoscopy in congenital heart surgery and in aortic valve repair has been reported previously. 1,2 In those reports, videoscopes were held by assistant surgeons. The view on the screen might therefore not be stable. In our technique, we use a videoscope holder to obtain a stable view on the video screen. Before cardiopulmonary bypass, a rigid 30-degree anged scope (A5288 OES TELESCOPE $30^{\circ}$; Olympus Optical Co. Ltd., Tokyo, Japan) is held by a videoscope holder with a flexible arm (Flex arm; Nisco Co. Ltd., Tokyo, Japan) fixed to the operating table (Fig. 1). The videoscope is connected to two video monitors and a video recorder. After the mitral valve is exposed through the combined transseptal superior approach, ${ }^{3}$ an assistant standing to the left of the operator introduces the videoscope into the left atrium (Fig. 2). The position of the videoscope is adjusted by bending the malleable arm of the holder. A magnified

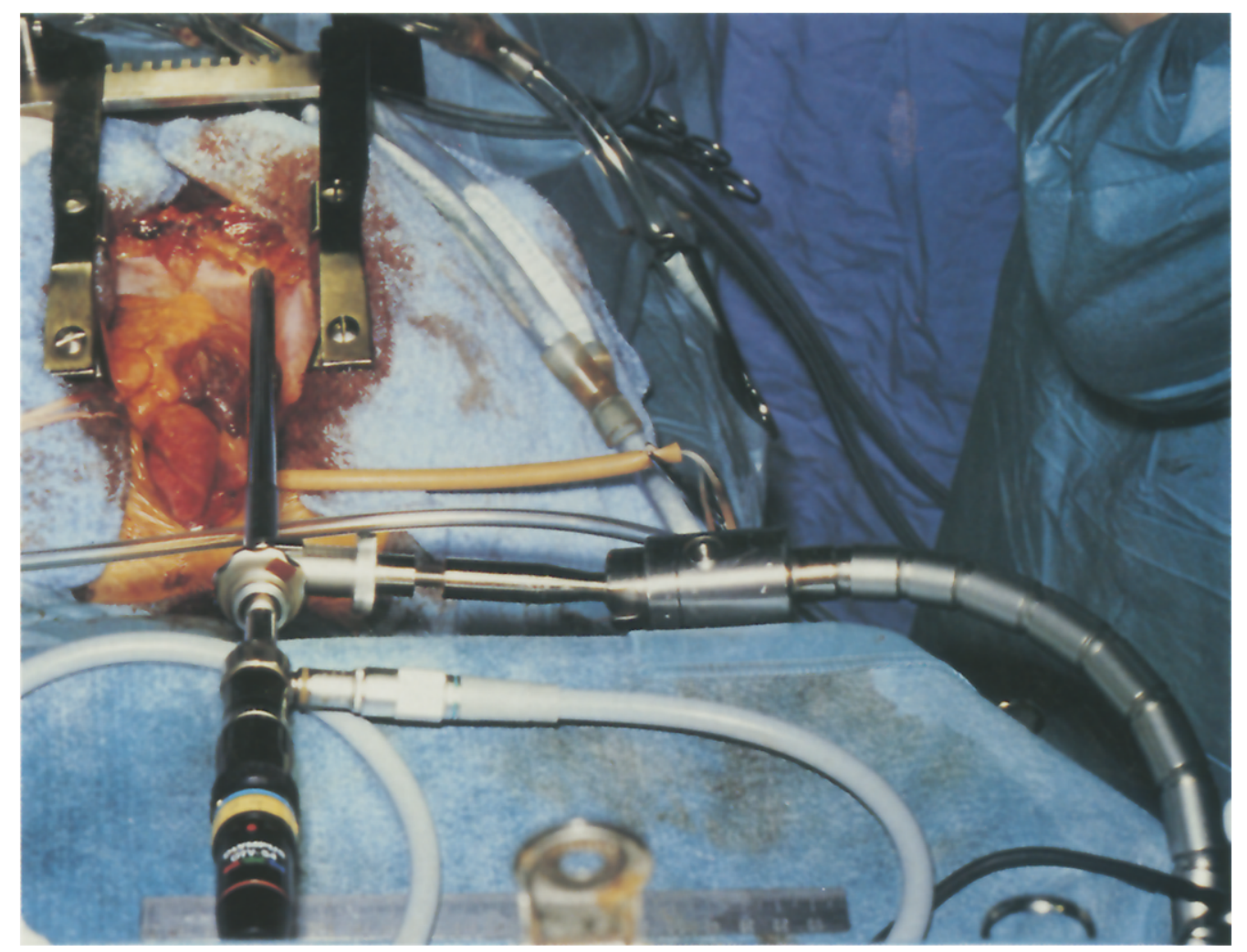

Fig. 1. Preoperative setup for viewing from the patient's cranial side. The videoscope is held by a holder with a flexible arm. 


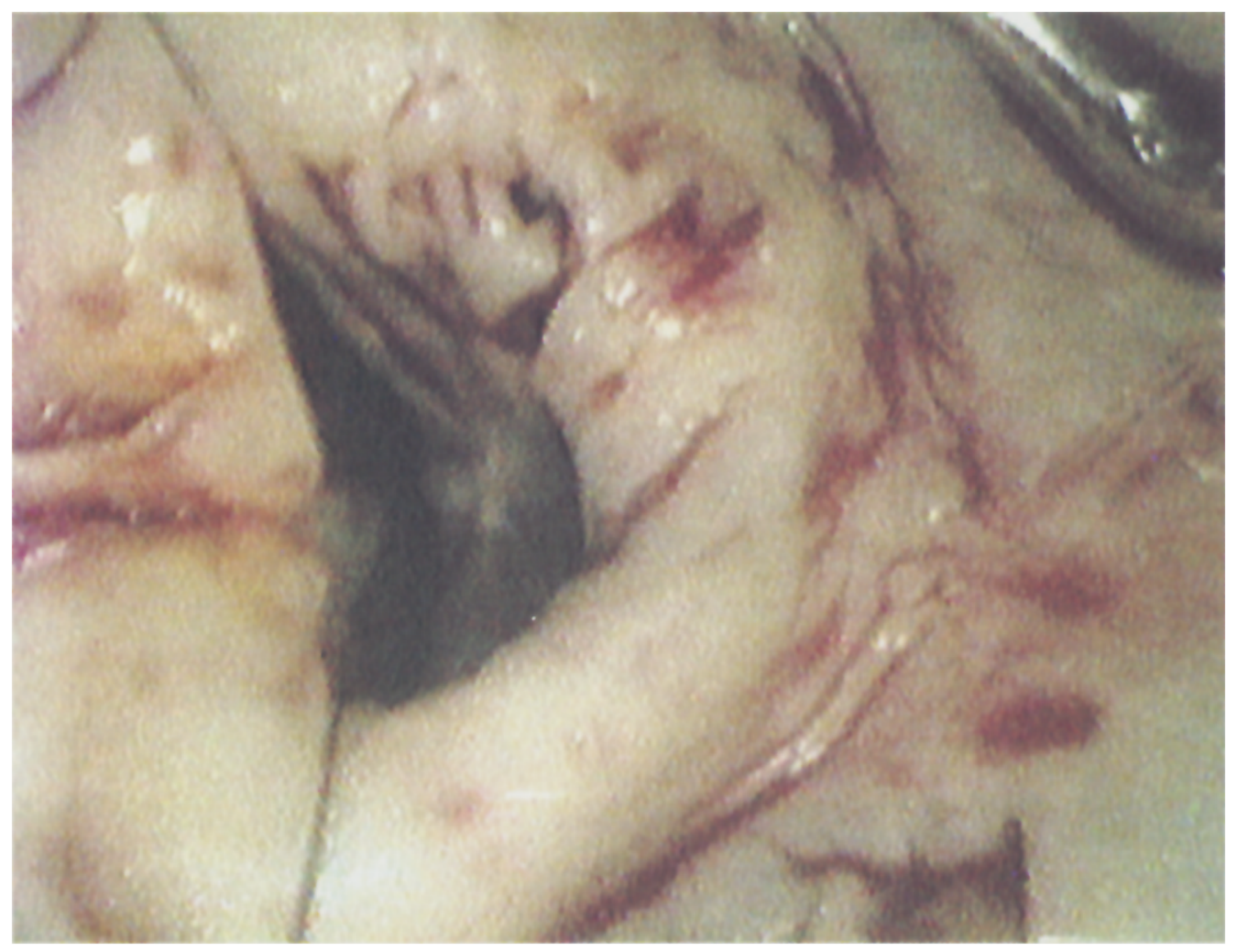

Fig. 2. View of a stenotic mitral valve through the videoscope. Fused anteromedial commissure and chordae from the posterior papillary muscle attached to the anterior leaflet can be seen.

view is obtained by placing the videoscope close to the valve. The subvalvular apparatus can be observed through the scope by inserting a small mirror into the left ventricle. By means of video assistance, the mitral valve can be observed from any desired direction and at desired magnification.

The operator can observe the mitral valve both directly and on the screen while carrying out the surgical maneuver. Illumination from the tip of the videoscope lights up the mitral valve, facilitating better observation even when the operator watches the valve directly. The video screen is much more informative than direct observation, and assistants are therefore able to assist the operation more efficiently. Video assistance is especially useful when an inexperienced resident performs the operation, because a senior surgeon can advise him or her in detail while watching the video screen. Anesthesiologists, cardiopulmonary bypass operators, residents, nurses, and students in the operating room can also watch the video screen. In addition, the surgical procedure can be recorded on a videotape much more clearly with the videoscope than with a video camera set behind the operator.
We have applied this method to several mitral commissurotomy and mitral valve repair operations without any obvious problems. The videoscope did not interfere with surgical maneuvers. We recommend this method for satisfactory mitral valve observation and clear recording of the operation.

\section{REFERENCES}

1. Burke RP, Michielon G, Wernovsky G. Video-assisted cardioscopy in congenital heart operations. Ann Thorac Surg 1994;58:864-8.

2. Furuse A, Kohno T, Ohtsuka T. Intraoperative visualization of the aortic valve from the left ventricle. $J$ Thorac Cardiovasc Surg 1995; 109:395.

3. Berreklouw E, Ercan H, Schönberger JP. Combined superior-transseptal approach to the left atrium. Ann Thorac Surg 1991;51:293-5. 